\title{
Lactic Acid Bacteria Fermented Cordyceps militaris (GRC-SC11) Suppresses IgE Mediated Mast Cell Activation and Type I Hypersensitive Allergic Murine Model
}

\author{
Abdul-Rehman Phull ${ }^{1,+}{ }^{+}$, Kyu-Ree Dhong ${ }^{2,+}$ and Hye-Jin Park ${ }^{1, *}$ \\ 1 Department of Food Science and Biotechnology, College of BioNano Technology, Gachon University, \\ Seongnam 13120, Gyeonggi-do, Korea; ab.rehman111@yahoo.com \\ 2 Department of Life Science, College of BioNano Technology, Gachon University, Seongnam 13120, \\ Gyeonggi-do, Korea; savanna123@gachon.ac.kr \\ * Correspondence: nimpi79@hanmail.net; Tel.: +82-31-750-5382 \\ + Both authors contributed equally to this study.
}

check for updates

Citation: Phull, A.-R.; Dhong, K.-R.; Park, H.-J. Lactic Acid Bacteria Fermented Cordyceps militaris (GRC-SC11) Suppresses IgE Mediated Mast Cell Activation and Type I Hypersensitive Allergic Murine Model. Nutrients 2021, 13, 3849. https://doi.org/10.3390/nu13113849

Academic Editor: Lindsay Brown and Katarzyna Śliżewska

Received: 23 September 2021

Accepted: 27 October 2021

Published: 28 October 2021

Publisher's Note: MDPI stays neutral with regard to jurisdictional claims in published maps and institutional affiliations.

Copyright: (c) 2021 by the authors. Licensee MDPI, Basel, Switzerland. This article is an open access article distributed under the terms and conditions of the Creative Commons Attribution (CC BY) license (https:// creativecommons.org/licenses/by/ $4.0 /)$.

\begin{abstract}
Cordyceps militaris (C. militaris) has various biomedical applications in traditional oriental medicine for different diseases including inflammatory and immune-dysregulated diseases. It is a reservoir of nutritional components such as cordycepin, polysaccharides, and antioxidants. To improve its bioactivity, we fermented C. militaris with a Pediococcus pentosaceus strain isolated from a salted small octopus (SC11). The current study aimed to evaluate whether P. pentosaceus (SC11) fermentation could enhance the anti-allergic potential of $C$. militaris cultured on germinated Rhynchosia nulubilis (GRC) against a type I hypersensitive reaction in in vitro and in vivo studies. Total antioxidant capacity and cordycepin content were significantly increased in GRC after SC11 fermentation. GRC-SC11 showed significantly enhanced anti-allergic responses by inhibiting immunoglobulin E (IgE)/antigen-induced degranulation in RBL-2H3 cells, compared to GRC. The results demonstrated the significant inhibition of phosphorylated spleen tyrosine kinase (Syk)/ p38/GRB2-associated binding protein 2 (Gab2)/c-jun in IgE/Ag-triggered RBL-2H3 cells. Furthermore, suppressed mRNA levels of interleukin-4 (IL-4) and tumor necrosis factor- $\alpha$ (TNF- $\alpha$ ) in IgE/Ag-activated RBL-2H3 cells were observed. GRC-SC11 significantly ameliorated IgE-induced allergic reactions by suppressing the ear swelling, vascular permeability, and inflammatory cell infiltration in passive cutaneous anaphylaxis (PCA) BALB/c mice. In conclusion, GRC fermented with P.pentosaceus exerted enhanced anti-allergic effects, and increased the cordycepin content and antioxidants potential compared to GRC. It can be used as bio-functional food in the prevention and management of type I allergic diseases.
\end{abstract}

Keywords: Cordyceps militaris; anti-allergy; fermentation

\section{Introduction}

Cordyceps militaris (C.militaris) is an important member of the Clavicipitaceae family. It is consumed as a traditional medicine for the treatment and management of several diseases, including inflammation and cancer, in East Asia [1,2]. C. militaris has various bioactive compounds including cordycepin, polysaccharides, adenosine, and ergosterol $[3,4]$. Due to exceptional habitats, such as dead insects, it is hard to find naturally grown C. militaris in the environment. However, the low extract yield and higher cost are the main hurdles for the commercial utilization of $C$. militaris.

It has been proven that fermented foods improve their bio-functionalities [5]. Lactobacillus strains isolated from dairy food products are used for a variety of food fermentation and applications [6]. Traditional food is considered to have several health benefits, and researchers have been striving to show the augmented biological capabilities of lactic acid bacteria (LAB) fermented foods. These bacterial strains are Gram-positive in their 
nature and may be found in a variety of foods, including meat, dairy products, and the digestive tract of humans. Various prebiotics, probiotics and postbiotics are known to possess anti-inflammatory, anti-carcinogenic, and other bioactivities [7]. Furthermore, LAB-associated fermentation can improve taste, texture, flavor, and preservation time, as well as physiological activities, including digestion efficiency and natural substance metabolism [8]. Cordyceps militaris using germinated Rhynchosia nulubilis (GRC) fermented with various microbial strains can be employed without costly extraction techniques and exhibits increased bio-activity. Our group used R. nulubilis as a culture substrate for the growth C. militaris, instead of the use of dead insects, and subsequently fermented it with Pediococcus pentosaceus isolated from the salted small octopus (SC11).

Approximately $20 \%$ of the world's population is affected by one or more allergic conditions. Various allergic conditions, such as anaphylaxis, allergic asthma, allergic rhinitis, atopic dermatitis, and food allergies, are also increasing at an alarming rate [9]. Although the signs of these allergic diseases vary, these conditions share common mechanisms at the molecular level. Mast cells are recognized for the manufacture and secretion of allergyassociated mediators, like histamine, chemokines, cytokines, and growth factors, which play a significant role in allergic diseases [10]. These components are found in vascularized tissues, particularly near surfaces exposed to the external environment, including the skin, gastrointestinal tract, and others [11,12]. The antigen cross-linking of immunoglobulin $\mathrm{E}(\mathrm{IgE})$ bound to $\mathrm{Fc}_{\mathrm{c}} \mathrm{RI}$ is required for mast cell activation. By cross-linking high-affinity IgE receptors, mast cells undergo degranulation, synthesis, and secretion of allergic related mediators, like histamine, cytokines, chemokines, and several enzymes [13,14]. Activated spleen tyrosine kinase (Syk), an Src family kinase, induces the phosphorylation of phosphoinositide 3-kinase, which induces phospholipase C (PLC) and serine-threonine kinase (Akt), preceded by calcium mobilization and activation of protein kinase $C$, mitogen-activated protein kinases (MAPKs), and nuclear factor (NF)- $\mathrm{kB}$ [15]. Among other mediators, histamine is a key component in acute allergic reactions because it induces vasodilation and enhanced vascular permeability, resulting in edema, hypothermia, and leukocyte recruitment. Mast cells release chemotactic and pro-inflammatory mediators, such as the tumor necrosis factor (TNF)- $\alpha$, interleukin (IL)-4, IL-1, and IL-8, during the late phase of the allergic phase [16]. Cytokines produced by mast cells alter the terminal microenvironment. Consequently, decreasing pro-inflammatory cytokines is critical for the management and treatment of allergic complications.

Despite the fact that the anti-allergic effects of $C$. militaris have been previously published, no comparative analysis of the anti-allergic effects of GRC-SC11 has been conducted so far. IgE/Ag-mediated passive cutaneous anaphylaxis (PCA) is one of the well-studied paradigms for testing the type- 1 hypersensitivity in vivo [17]. Mast cells are also used to study anti-allergic responses linked to the reduced mast cell degranulation and expression of inflammatory cytokines. In this study, we investigated whether P. pentosaceus (SC11) fermentation on GRC enhanced its bio-functional nature, and inhibited type I hypersensitivity reactions in RBL-2H3 cells and in mice.

\section{Materials and Methods}

\subsection{Production of GRC Fermented with P. pentosaceus}

The extract of the GRC sample was produced using patented technologies (Cell Activation Research Institution, Seoul, Korea; voucher specimen Kucari: 0903). Fermentation of GRC was carried out as per the previously described method (Kwon et al., 2018) using lactic acid bacterial strain P. pentosaceus isolated from the salted small octopus kindly gifted from Prof. Dr. Y.S. Park. The water extract of GRC $(5 \% w / v)$ was prepared at $100{ }^{\circ} \mathrm{C}$ for $2 \mathrm{~h}$ and then cultured with the SC11 bacterial strain for $24 \mathrm{~h}$. P. pentosaceus strains were heat inactivated for $10 \mathrm{~min}$ at $100{ }^{\circ} \mathrm{C}$. After being sonicated for $3 \mathrm{~min}$ (Sonics \& Materials Inc., Newtown, CT, USA), the extract was filtered through $0.45 \mu \mathrm{M}$ filters to remove bacteria and then was sterilized. 


\subsection{Cell Viability Assay}

A cell viability assay was carried out to evaluate whether GRC-SC11 had any toxic effects on RBL-2H3 cells, as in the previously described method [18]. The assay was performed using Cell Counting Kit-8 (CCK-8 (WST-8); Dojindo Laboratories, Kumamoto, Japan). Briefly, cells were plated at a concentration of $2 \times 10^{4}$ /well in a 96-well plate and incubated in a carbon dioxide $\left(\mathrm{CO}_{2}\right)$ humidified incubator (Thermo Fisher Scientific 3111, Thermo Fisher Scientific, Waltham, MA, USA) at $37^{\circ} \mathrm{C}$ overnight. Viability was determined by measuring the absorbance at $450 \mathrm{~nm}$ using a microplate reader (Epoch; Biotek Instruments Inc., Winooski, VT, USA). Non-treated cells (control) were considered 100\% viable. The treated cells were compared with the control and expressed as a percentage relative to that of the control.

\section{3. $\beta$-Hexosaminidase Assay}

The $\beta$-hexosaminidase assay was performed as per the previous study [15]. RBL-2H3 cells were treated with $200 \mathrm{ng} / \mathrm{ml}$ of dinitrophenyl (DNP) specific IgE (Sigma-Aldrich, St. Louis, MO, USA). After being incubated overnight, cells were washed with the PIPES buffer ( $25 \mathrm{mM}$ PIPES at pH 7.2, $119 \mathrm{mM} \mathrm{NaCl}, 5 \mathrm{mM} \mathrm{KCl}, 1 \mathrm{mM} \mathrm{CaCl} 2,0.4 \mathrm{mM} \mathrm{MgCl}_{2}$ $6 \mathrm{H}_{2} \mathrm{O}, 40 \mathrm{mM} \mathrm{NaOH}, 5.6 \mathrm{mM}$ glucose, and $0.1 \%$ bovine serum albumin (BSA)). GRC, GRC-SC11, or PP2 (Calbiochem, La Jolla, CA, USA) were treated for $30 \mathrm{~min}$. Cells were stimulated with DNP-BSA (200 ng/ml, antigen; Sigma-Aldrich, St. Louis, MO, USA) for $15 \mathrm{~min}$ at $37^{\circ} \mathrm{C}$. The absorbance was measured at $405 \mathrm{~nm}$ by a microplate reader (Epoch BioTek Instruments, Winooski, VT, USA).

\subsection{Reverse Transcription-Polymerase Chain Reaction (RT-PCR)}

The RT-PCR was performed by following the previously described method $[19,20]$. Total RNA from RBL-2H3 cells was prepared using the TRIzol reagent (Invitrogen, Carlsbad, CA, USA) and reverse-transcribed using the ReverTra Ace qPCR RT kit (Toyobo Biologics Inc., Osaka, Japan). A polymerase chain reaction (PCR) was performed according to the manufacturer's protocol (Qiagen, Hilden, Germany). The PCR program for IL-4 was performed as follows: initial denaturation at $94^{\circ} \mathrm{C}$ for $2 \mathrm{~min}$, followed by 30 cycles of denaturation at $94{ }^{\circ} \mathrm{C}$ for $20 \mathrm{~s}$, annealing at $56{ }^{\circ} \mathrm{C}$ for $10 \mathrm{~s}$, and extension at $72{ }^{\circ} \mathrm{C}$ for $25 \mathrm{~s}$, with a final extension at $72{ }^{\circ} \mathrm{C}$ for $5 \mathrm{~min}$. The PCR program for TNF- $\alpha$ was performed as follows: "initial denaturation at $94{ }^{\circ} \mathrm{C}$ for $2 \mathrm{~min}$, followed by 30 cycles of denaturation at $94{ }^{\circ} \mathrm{C}$ for $20 \mathrm{~s}$, annealing at $62.2^{\circ} \mathrm{C}$ for $10 \mathrm{~s}$, and extension at $72{ }^{\circ} \mathrm{C}$ for $45 \mathrm{~s}$, with a final extension at $72{ }^{\circ} \mathrm{C}$ for $5 \mathrm{~min}$. The PCR program for glyceraldehyde 3-phosphate dehydrogenase (GAPDH) was performed as follows: "initial denaturation at $94{ }^{\circ} \mathrm{C}$ for $2 \mathrm{~min}$, followed by 30 cycles of denaturation at $94{ }^{\circ} \mathrm{C}$ for $20 \mathrm{~s}$, annealing at $62{ }^{\circ} \mathrm{C}$ for $10 \mathrm{~s}$, and extension at $72{ }^{\circ} \mathrm{C}$ for $25 \mathrm{~s}$, with a final extension at $72{ }^{\circ} \mathrm{C}$ for $5 \mathrm{~min}$. The following primers were used: TNF- $\alpha$ forward " $\left(5^{\prime}\right.$-CACCACGCTCTTCTGTCTACTGAAC$\left.3^{\prime}\right)$ "; TNF- $\alpha$ reverse " $\left(5^{\prime}\right.$-CCGGACTCCGTGATGTCTAAGTACT- $\left.3^{\prime}\right)$ "; IL-4 forward " $\left(5^{\prime}-\right.$ ACCTTGCTGTCACCCTGTTC- $\left.3^{\prime}\right)^{\prime \prime}$; IL-4 reverse "(5'-TTGTGAGCGTGGACTCATTC-3'; and GAPDH reverse 5'-GACCACAGTCCATGCCATCACTG-3')" (Cosmo Genetech, Seoul, South Korea). Finally, PCR products were resolved by electrophoresis using 1.5\% agarose gels. The resolved bands were examined under the LI-COR Odyssey system (LI-COR Biosciences Inc., Lincoln, NE, USA).

\subsection{Immunoblotting}

Western blotting was performed as described following the previous method [21]. Cells $\left(1 \times 10^{6}\right.$ cells /well $)$ were harvested and homogenized in the radioimmunoprecipitation assay cell lysis buffer (Cell Signaling Technology, Beverly, MA, USA). Protein concentrations were measured using a BCA protein assay kit (Thermo Scientific, Rockford, IL, USA). Proteins $(80 \mu \mathrm{g})$ were resolved using $10 \%$ sodium dodecyl sulfate-polyacrylamide gel. Subsequently, resolved proteins were transferred to nitrocellulose membranes. Membranes were blocked in 5\% BSA for one hour. The blots were washed with Tris-buffered saline 
with Tween 20 buffer (TBST) and incubated with primary antibodies: phosphorylated-Syk (Cell Signaling Technology), phosphorylated-Gab (Cell Signaling Technology), phosphorylated c-Jun (Cell Signaling Technology), and $\beta$-actin (Cell Signaling Technology). The immunoblots were washed in TBST(Bio-Rad Laboratories, Hercules, CA, USA) and incubated with horseradish peroxidase-labeled secondary antibody (Cell Signaling Technology). The immuno blots were developed using EZ west Lumi plus (Atto, Tokyo, Japan). Finally, developed immuno blots were visualized, and a densitometry analysis of the bands was performed using LI-COR Odyssey (LI-COR Biosciences, Lincoln, NE, USA).

\subsection{Experimental Animals}

Seven-week-old male BALB/c mice were obtained from a Korean company (Orient Bio Inc., Seongnam, Korea). All the experimental animals were kept in aluminum cages under controlled pathogen-free conditions, such as $55 \pm 5$ humidity, $12 \mathrm{~h} \mathrm{light/dark} \mathrm{cycle,}$ $24 \pm 2{ }^{\circ} \mathrm{C}$ temperature, and provided with standard feed along with water ad libitum. Animals were maintained in accordance with the guidelines of the Institutional Animal Care and Use Committee of Gachon University, Seongnam, Gyeonggi-do 461-701, South Korea (GIACUC- R2018001). All experimental mice were separated into four groups and comprised of six male BALB/c mice. Specified doses of GRC-SC11 and the reference drug were administered orally by gavage.

Group I: Normal control (non-treated)

Group II: Passive cutaneous anaphylaxis (PCA) disease control $(0.5 \mu \mathrm{g}$ IgE, anti- DNP IgE sensitized and challenged with $200 \mu \mathrm{g}$ DNP-HAS $+2 \%$ Evans blue solution)

Group III: PCA mice treated with GRC-SC11 $(100 \mathrm{mg} / \mathrm{kg})$

Group IV: PCA mice treated with the reference drug control $(10 \mathrm{mg} / \mathrm{kg})$.

\subsubsection{PCA BALB/c Mice Model}

The PCA assay was performed as described previously in a study [22]. For the PCA reaction, BALB/c mice were intravenously injected with PBS solution containing $200 \mu \mathrm{g}$ DNP-BSA and $2 \%(w / v)$ Evans blue solution $24 \mathrm{~h}$ after the intradermal injection of $0.5 \mu \mathrm{g}$ anti-DNP IgE into one ear per mouse. In order, to investigate the inhibitory potential in the animals, each PCA mouse was orally administered with $100 \mathrm{mg} / \mathrm{kg}$ of sample one hour before DNP-BSA. Cetirizine was used as a standard drug at the concentration of $10 \mathrm{mg} / \mathrm{kg}$. One hour after the challenge, the mice were euthanized using $\mathrm{CO}_{2}$ and sacrificed. The ears were collected for histological investigation and extraction of the Evans blue dye. Extravasated Evans blue dye was extracted by incubating the ear biopsies in formamide at $60^{\circ} \mathrm{C}$ for $16 \mathrm{~h}$. Optical densities were recorded at $620 \mathrm{~nm}$ using a microplate reader (Tecan, Männedorf, Switzerland).

\subsubsection{Histopathologic Assessment}

Histopathological investigations were carried out using a previously described method with slight modifications [22]. The ear biopsies were fixed in formalin (10\%), embedded in paraffin, and stained with hematoxylin and eosin (Sigma-Aldrich, St. Louis, MO, USA). Generally, the extracellular matrix and cytoplasm were stained pink with eosin, while the nuclei were stained blue with the hematoxylin dye. The images of hematoxylin and eosin-stained tissues were taken using a Nikon Eclipse Ti incorporated CCD camera at $100 \times$ and $200 \times$ (Nikon, Melville, NY; Point Grey Research Inc., Richmond, BC, Canada). Stained cells were measured using the ImageJ software (1.46, National Institutes of Health, Bethesda, MD, USA).

\subsection{High-Performance Liquid Chromatography (HPLC) Analysis for Cordycepin}

Cordycepin (3'-deoxyadenosine) was determined in GRC and GRC-SC11 using HPLC (Agilent 1100 liquid chromatography system: Palo Alto, CA, USA). The measurement data were provided by the Korea Basic Science Institute (KBSI) on the Ochang Campus, South Korea. Waters Acquity BEH C18 columns $(100 \mathrm{~mm} \times 2.1 \mathrm{~mm}$ id, $1.7 \mu \mathrm{m}$ and 
$12.5 \mathrm{~mm} \times 4.6 \mathrm{~mm}$ id, $5 \mu \mathrm{m}$ ) were used. Water and methanol were used as mobile phases with a flow rate of $1.0 \mathrm{~mL} / \mathrm{min}$. UV detection was performed at the $254 \mathrm{~nm}$ wavelength. A calibration curve was prepared by plotting the peak area against the concentration using different concentrations of cordycepin (Sigma-Aldrich, St. Louis, MO, USA).

\subsection{Total Antioxidant Capacity (TAC) Assay}

The TAC of the samples was investigated using the phosphomolybdenum method. the TAC activity was expressed as ascorbic acid equivalents (AAE). Briefly, $100 \mu \mathrm{L}$ of the extract and $400 \mu \mathrm{L}$ of the reagent solution (ammonium molybdate $(4 \mathrm{mM}$ ), sodium phosphate $(28 \mathrm{mM})$, and sulfuric acid $(0.6 \mathrm{M}))$ were mixed. The assay mixture was incubated at $95{ }^{\circ} \mathrm{C}$ for $90 \mathrm{~min}$ and cooled at an ambient temperature, and the optical density was recorded at $695 \mathrm{~nm}$ using an OPTIMax tunable microplate reader (Molecular Devices; Sunnyvale, CA, USA). Ascorbic acid was used as the reference antioxidant, and ascorbic acid equivalents (AAE) were calculated using a standard curve. The antioxidant activity of the sample was expressed as $\mu \mathrm{g}$ or $\mathrm{mg}$ ascorbic acid equivalent per mg of extract ( $\mu \mathrm{g} \mathrm{AAE} / \mathrm{mg}$ or mg AAE/g).

\subsection{Statistical Analysis}

Results are presented as representative or mean \pm standard deviation (SD) and were analyzed by using a one-way analysis of variance (ANOVA), followed by Duncan's $t$-test, Student's $t$-test, or Dunnett's $t$-test. The normality distribution of all data was checked by the Shapiro Wilk test. Data were analyzed using the SPSS v.12 software (SPSS Inc., Chicago, IL, USA).

\section{Results}

\subsection{Effect of P. pentosaceus SC11 Mediated Fermentation on the Antioxidant Potential and Cordycepin Content of Cultured C. militaris}

Fermentation has various beneficial effects in improving the nutritional and bio functional properties of food. To examine the antioxidant activities of GRC and GRC-SC11, the extracts of both samples were examined using a TAC assay. Fermentation improved the antioxidant potential of GRC-SC11, which exhibited higher activity than GRC (Figure 1). In addition, increased cordycepin contents as $126.46 \pm 6.52 \mu \mathrm{M}$ and $179.49 \pm 10.68 \mu \mathrm{M}$ were observed in GRC-SC11, respectively. These results are shown in Figure 1.

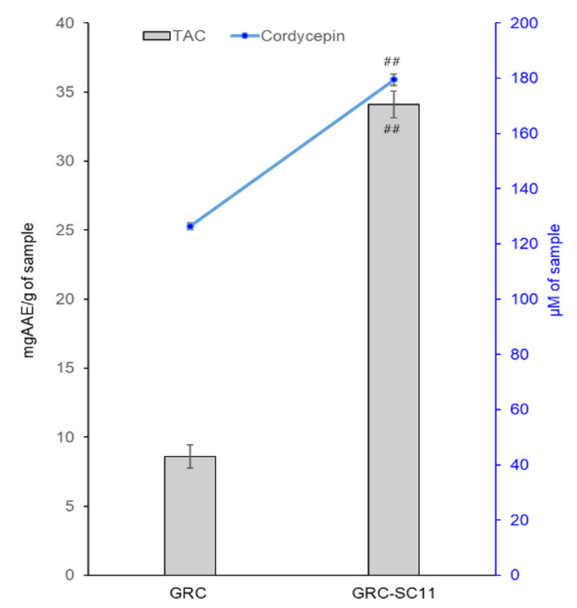

Figure 1. Total antioxidant capacity (TAC) and cordycepin content of $C$. militaris grown on germinated R. nulubilis (GRC) and GRC fermented by P. pentosaceus isolated from the salted small octopus (SC11) (GRC-SC11). The experiments were repeated three times and results are presented as mean \pm SD. TAC was expressed as mg ascorbic acid equivalent (mgAAE). Results were considered significant at the $p$ value of \#\# $p<0.01$. Data comparisons between the two groups were analyzed using the Student's t-test. 


\subsection{Effect of GRC and GRC-SC11 on IgE/Ag-Activated Degranulation of RBL-2H3 Cells}

To select the best LAB strain for fermenting GRC, we compared the inhibitory activity on degranulation of IgE/Ag-stimulated RBL-2H3 cells. Among them, P. pentosaceus SC11 exerted the highest inhibitory activity on the release of $\beta$-hexosaminidase (Supplement Figure S1, Table S1); therefore, we chose P. pentosaceus SC11 for fermenting GRC for further anti-allergic study. To evaluate the anti-allergic potential of GRC and GRC-SC11 extracts, we examined their effects on IgE/Ag-triggered degranulation in RBL-2H3 cells. $\beta$-hexosaminidase release was quantified [19]. The results showed that GRC-SC11 exhibited a higher inhibitory effect on $\beta$-hexosaminidase release through the degranulation index (Figure 2A). To investigate the effect of GRC-SC11 on cell viability, a CCK8 assay was performed. RBL-2H3 cells were untreated or treated with different concentrations of GRC-SC11 for $24 \mathrm{~h}$. The results showed that GRC-SC11 did not exhibit any toxic effect and subsequently did not alter the viability of RBL-2H3 cells up to $300 \mu \mathrm{g} / \mathrm{mL}(p<0.05)$ (Figure 2B). Henceforth, GRC-SC11 was selected for further study.

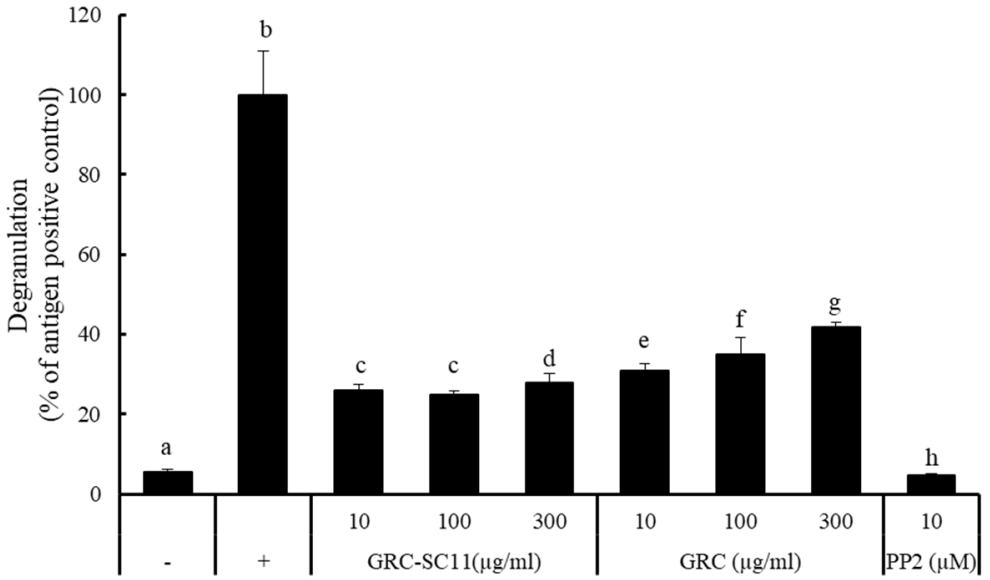

(A)

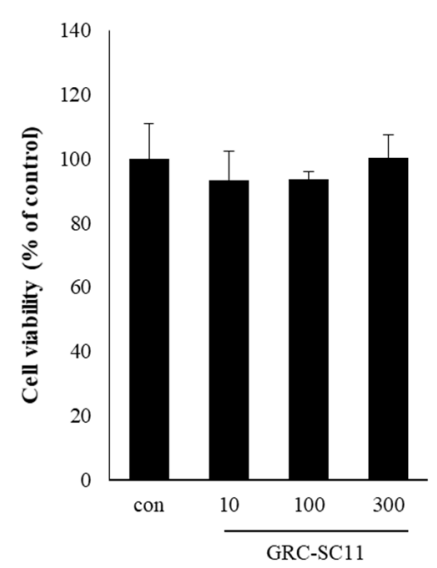

(B)

Figure 2. Effects of GRC and GRC-SC11 on degranulation and cell viability of RBL-2H3 cells. (A) The release of $\beta$-hexosaminidase was calculated from the degranulation of RBL-2H3 cells. RBL-2H3 cells were treated with the indicated concentrations of GRC and GRC-SC11 and $10 \mu \mathrm{M}$ 4-amino-5-(4-chlorophenyl)-7-(t-butyl) pyrazolo (3, 4-d) pyrimidine (PP2) for $30 \mathrm{~min}$. Control (-) is the untreated control, while control (+) is stimulated with immunoglobulin E (IgE)/ Ag. PP2 is an Src family kinase inhibitor that was used as the positive control. Different letters indicate the significant differences between groups. Results were compared for statistical significance through a one-way analysis of variance (ANOVA) followed by Duncan's $t$-test $(p<0.05)$. (B) RBL-2H3 cells were exposed to different concentrations $(10,100$, and $300 \mu \mathrm{g} / \mathrm{mL})$ of GRC-SC11 for $24 \mathrm{~h}$ and cell viability was investigated. The experiments were repeated three times and results are presented as the representative or mean $\pm \mathrm{SD}$. Results were compared for statistical significance through a one-way analysis of variance (ANOVA followed by Duncan's $t$-test $(p<0.05)$ ).

\subsection{Effect of GRC-SC11 Pro-Inflammatory Cytokines in IgE/Ag-Stimulated RBL-2H3 Cells}

We assessed GRC-SC11 reduced IgE/Ag-stimulated TNF- $\alpha$ and IL-4 mRNA expression through RT-PCR in RBL-2H3 cells. The IgE/Ag-stimulated production of IL-4 and TNF- $\alpha$ in RBL-2H3 is associated with the synthesis of inflammatory mediators, such as reactive oxygen species, nitric oxide, chemokines and other cytokines, and induces IgE antibody generation in B cells [23]. GRC-SC11 significantly suppressed TNF- $\alpha$ mRNA expression in a dose-dependent manner. GRC-SC11 also decreased IL-4 mRNA expression in RBL-2H3 treated with IgE/Ag. (Figure 3A,B). 


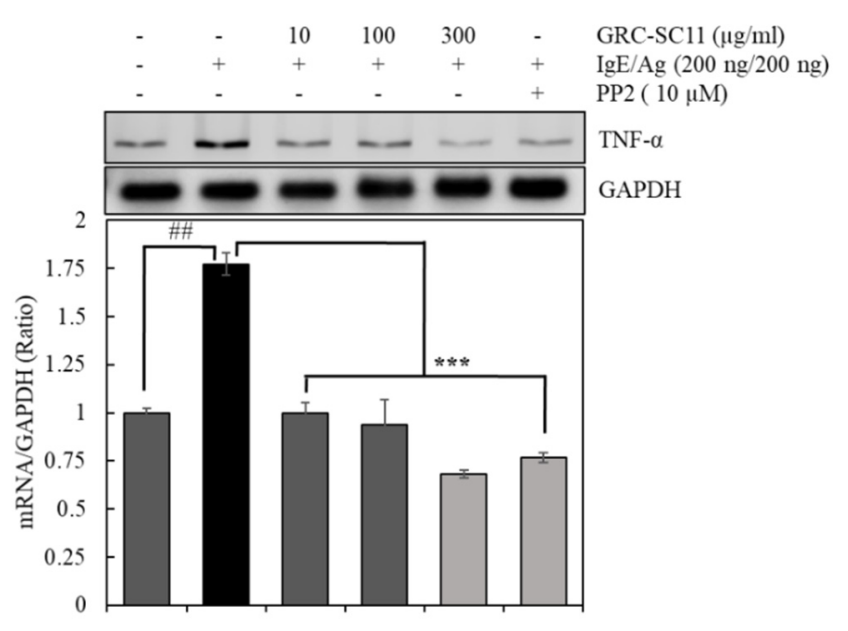

(A)

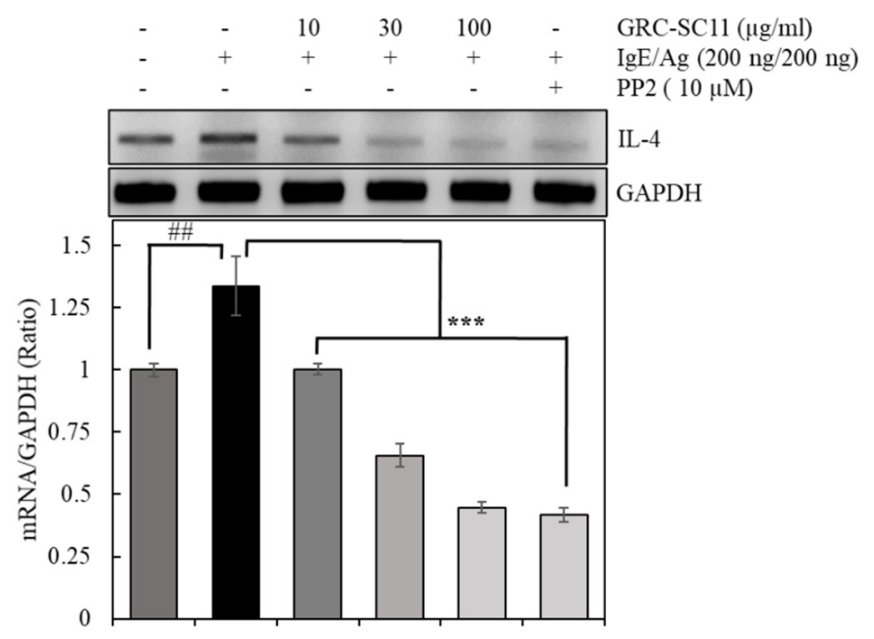

(B)

Figure 3. Effect of GRC-SC11 on the production of pro-inflammatory cytokines in IgE/Ag-stimulated RBL-2H3 mast cells. The RBL-2H3 cells were untreated or treated with indicated concentrations of GRC-SC11 in the absence or presence of the $200 \mathrm{ng} / \mathrm{mL}$ of $\mathrm{IgE} / \mathrm{Ag}$ or $10 \mu \mathrm{M}$ of PP2. GRC-SC11 reduced the expressions of (A) tumor necrosis factor (TNF)- $\alpha$ and (B) interleukin (IL)-4 in IgE/Ag-stimulated RBL-2H3 mast cells. The expression study was carried out by Western blotting method using GAPDH as the loading control. The relative amounts of TNF- $\alpha$, IL- 4 were analyzed by using the Image J software. The results are presented as the representative or mean $\pm \mathrm{SD}$ of three independent experiments. Results were analyzed for statistical significance through a one-way ANOVA followed by Dunnett's $t$-test. The probability value of \#\# $p<0.01$ was considered significant compared to the non-treated cells and ${ }^{* * *} p<0.01$ compared to the IgE/Ag-treated cells.

\subsection{Effect of GRC-SC11 on IgE/Ag Associated Signaling Molecules in RBL-2H3 Cells}

The crosslinking of $\mathrm{Ag}$ with IgE-stimulated FceRI receptors in mast cells leads to the triggering of diverse intracellular signaling cascades, inducing the degranulation and production of pro-inflammatory cytokines. During the FceRI signaling pathway, activated Src family kinases such as Lyn and Syk phosphorylate downstream molecules (GRB2associated binding protein 2 (IL-4)) and mitogen-activated protein kinase (MAPK) [24]. To elucidate the anti-allergic effect of GRC-SC11 on the activation of the FceRI and MAPK signaling pathways, we assessed whether GRC-SC11 decreased the levels of phosphorylated Syk, Gab2, p38, and c-Jun proteins in RBL-2H3 cells treated with IgE/Ag. GRC-SC11 significantly suppressed the levels of phosphorylated Syk, Gab2, p38, and c-Jun proteins, compared to IgE/ Ag-stimulated controls (Figure $4 \mathrm{~A}, \mathrm{~B}, p<0.001$ and $p<0.05$ ). The findings of this study indicated that GRC-SC11 downregulated allergy associated signaling molecules of FceRI and MAPK pathways in IgE/Ag-stimulated RBL-2H3 cells.

\subsection{Effect of GRC-SC11 on the PCA Model}

A PCA mouse model was used to study the immediate-type allergic reactions (Figure 5A). To induce PCA in the murine ear, mice were stimulated with IgE in the ear and this was challenged by injecting DNP-BSA containing $1 \%$ Evans blue dye into the tail vein. Blue spots were developed in the ear of mice stimulated with $\mathrm{IgE} / \mathrm{Ag}$. This was due to the augmented vascular permeability induced by histamine released from RBL-2H3 cells. The results demonstrated a prominent increase in Evans blue staining in the PCA model $(p<0.001)$. GRC-SC11 $(100 \mathrm{mg} / \mathrm{kg})$ and the reference drug $(10 \mathrm{mg} / \mathrm{kg})$ significantly suppressed dye extravasation $(p<0.001)$ (Figure 5B,C). The data showed that GRC-SC11 decreased the $\mathrm{IgE} / \mathrm{Ag}$-stimulated PCA response in BALB/c mice. 


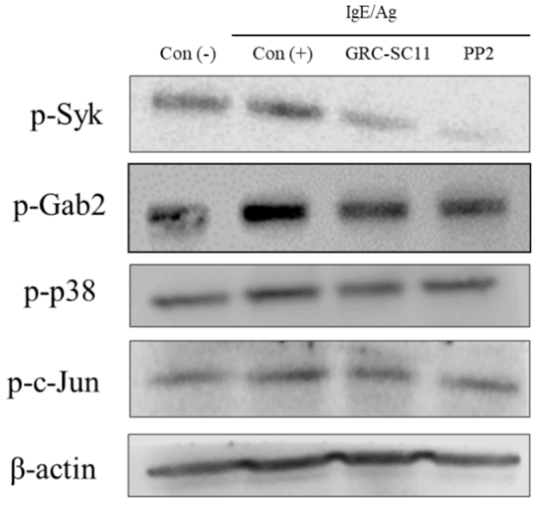

(A)
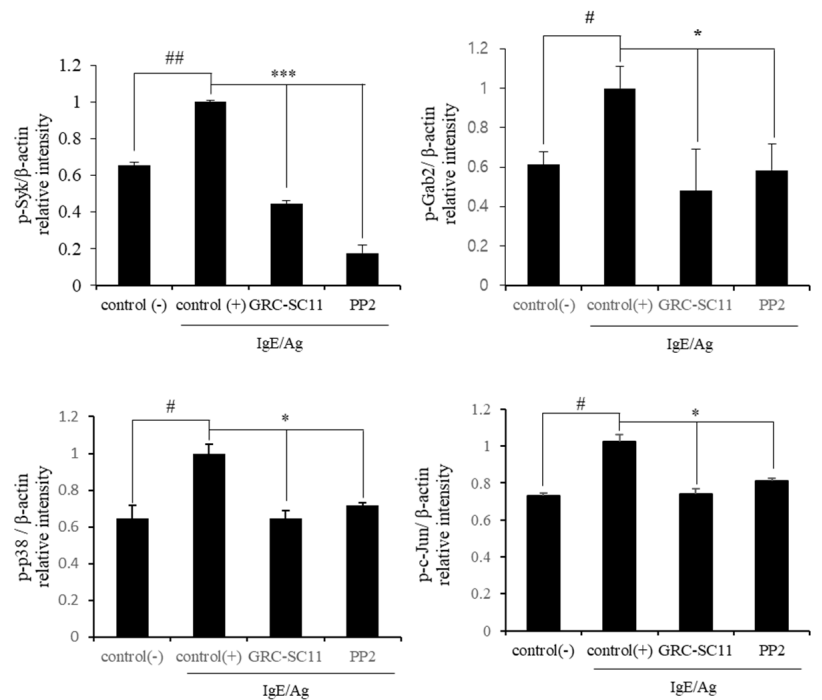

(B)

Figure 4. Effects of GRC-SC11 on the signaling molecules IgE/Ag-activated RBL-2H3 cells. RBL-2H3 cells were sensitized with dinitrophenol (DNP)-IgE and then stimulated with antigen for $15 \mathrm{~min}$. (A) Western blotting assay of phospho-spleen tyrosine kinase (p-Syk), Syk, phospho-GRB2-associated binding protein 2 (p-Gab2), Gab2, p-p38, and p-c-Jun. (B) Expression levels of GRC-SC11. The levels were normalized to $\beta$-actin levels. The experiments were repeated three times and results are presented as the representative or mean $\pm \mathrm{SD}$. The probability values of \# $p<0.05$ and \#\# $p<0.01$ were considered to be significant compared to the non-treated cells, and ${ }^{*} p<0.05$ and ${ }^{* * *} p<0.001$ compared to the IgE/Ag treated cells. One-way ANOVA was used for the comparison of group means, followed by Dunnett's $t$-test.

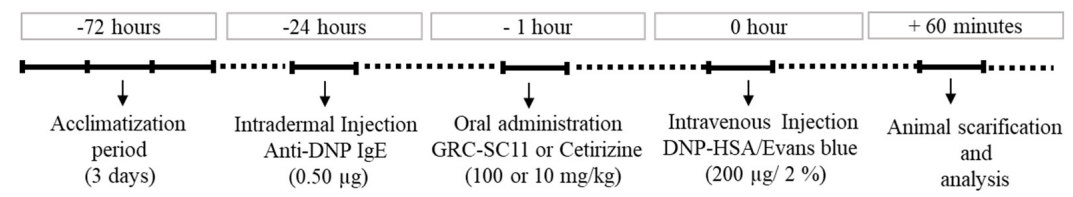

(A)

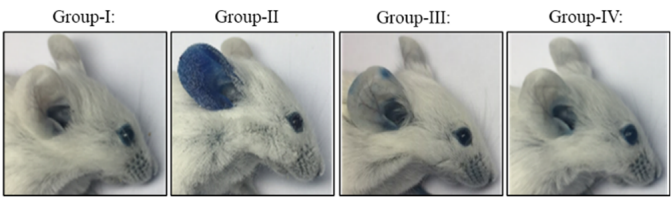

(B)

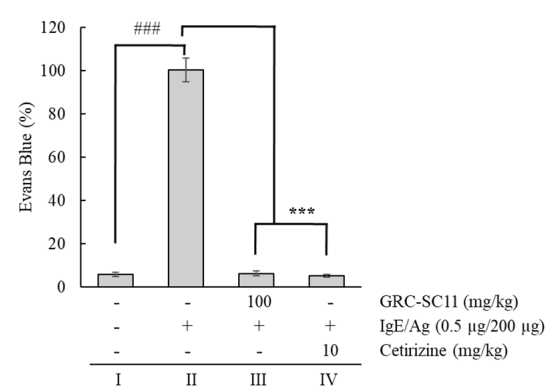

(C)

Figure 5. Effect of GRC-SC11 on the IgE/Ag-stimulated passive cutaneous anaphylaxis (PCA) BALB/c mice model. (A) Scheme of the PCA design. PCA was induced by subcutaneous injection of $0.5 \mu \mathrm{g}$ of DNP-specific IgE into the ear of male BALB/c mice for $24 \mathrm{~h}$ and followed by the intravenous administration of $200 \mu \mathrm{g}$ of DNP-bovine serum albumin (BSA) antigen having $2 \%$ Evans blue dye in the tail region. Anti-allergic activity of GRC-SC11 was assessed at the concentration of $100 \mathrm{mg} / \mathrm{kg}$, while cetirizine was used as the standard drug (10 mg/kg). Group I: Normal control (non-treated). Group II: PCA disease control (0.5 $\mu \mathrm{g}$ IgE, anti-dinitrophenyl (DNP) IgE sensitized and challenged with $200 \mu \mathrm{g}$ DNP-HAS + 2\% Evans blue solution). Group III: PCA mice treated with GRC-SC11 (100 mg/kg). Group IV: PCA mice treated with the reference drug control (10 mg/kg). (B) Representative image of murine ear ( $n=7$ mice/group). (C) The mean \pm SD of extravasated dye ( $n=7$ mice/group). Differences were significant at the level of \#\#\# $p<0.001$ (compared with normal animals) and *** $p<0.001$ (compared with normal PCA animals). Statistical analysis of results was performed through one-way ANOVA followed by Dunnett's $t$-test. 


\subsection{Effect of GRC-SC11 on Histopathological Changes and Ear Swelling Response in the PCA $B A L B / c$ Mice Model}

To examine the consequences of GRC-SC11 on ear tissue and ear swelling response in a PCA animal model, the ear biopsies were stained with hematoxylin and eosin. Skin swelling due to augmented vascular permeability-associated histamine secretion from cells at the PCA site was observed, and this effect could also be attributed to the increased number of infiltrated immune cells. GRC-SC11 $(100 \mathrm{mg} / \mathrm{kg})$ and the reference $(10 \mathrm{mg} / \mathrm{kg})$ significantly reduced the ear thickness and infiltrated immune cells compared to that in the PCA mice model. Collectively, these data showed that GRC-SC11 attenuated the IgE/ Agstimulated infiltration of inflammatory cells along with increased dermal and epidermal ear thickness in IgE/Ag-stimulated mice (Figure 6A,B).
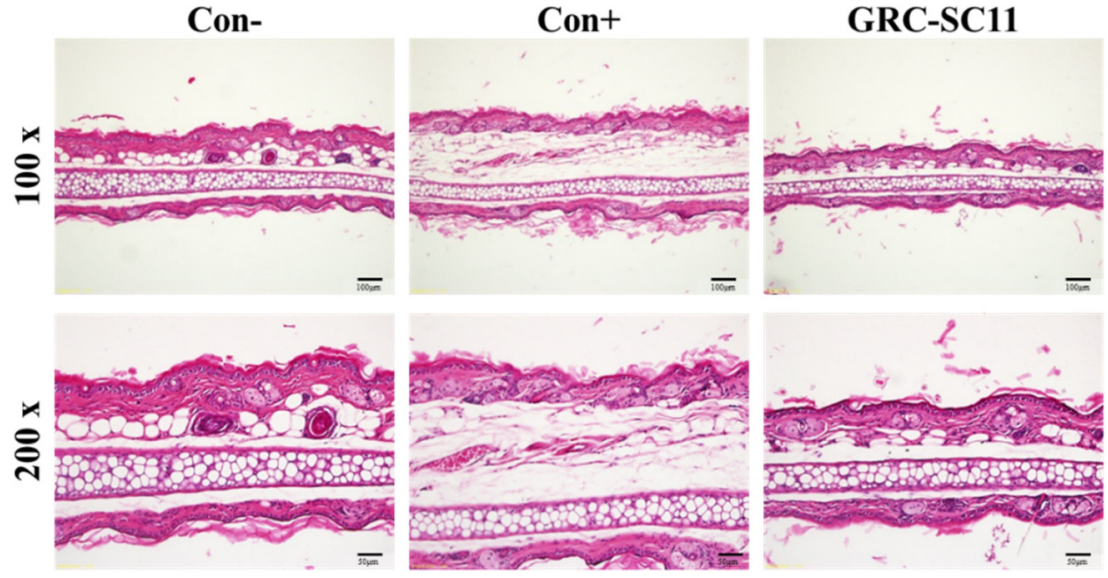

(A)

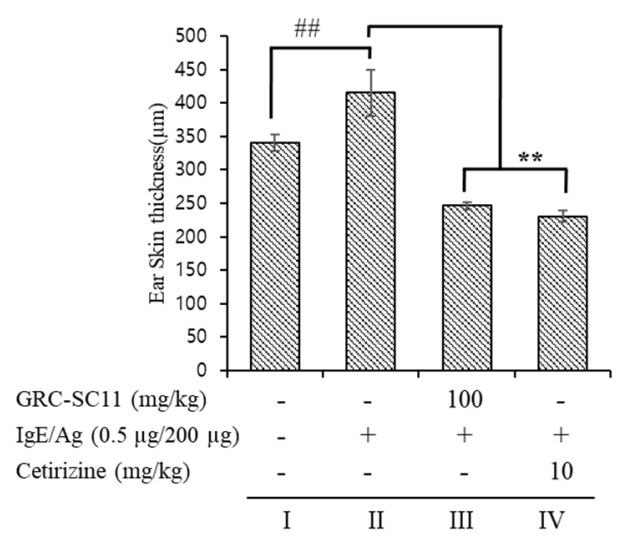

(B)

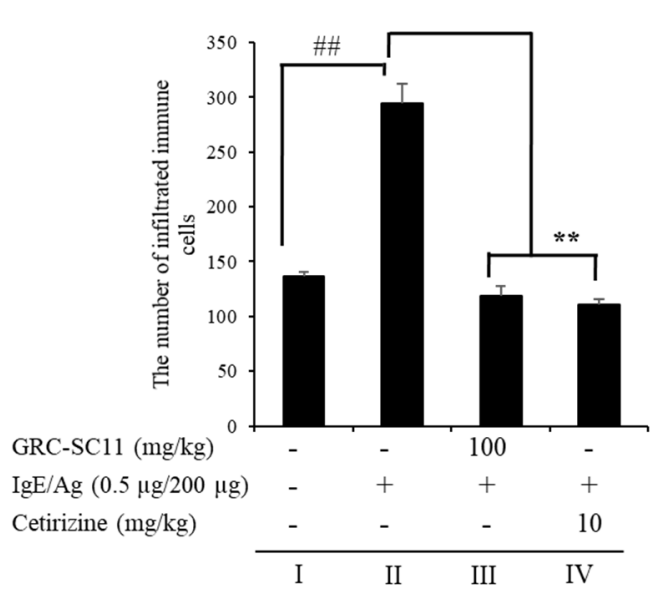

(C)

Figure 6. Effect of GRC-SC11 on IgE/Ag-induced ear swelling response in the BALB/c mice models. Histopathological examination of ear tissues of the IgE/Ag-triggered PCA BALB/c mice models. (A) Representative images of ear tissues stained with hematoxylin and eosin ( $n=7$ /group; magnifications, $100 \times$ and $200 \times)$ of group-I: normal control, group-II: PCA disease control (IgE/Ag, anti-DNP IgE sensitized and DNP-HAS challenged), group-III: GRC-SC11 (100 mg/kg), and group-IV: drug control $(10 \mathrm{mg} / \mathrm{Kg})$. (B) A dial thickness gauge was used to measure ear thickness. Data are expressed as mean $\pm \mathrm{SD}$ ( $n=7$ /group). (C) Infiltrated immune cells were counted in the ear of mice. Data are expressed as mean $\pm \mathrm{SD}$ ( $n=7$ /group). Results were considered significant at the level of \#\# $p<0.01$ (compared with normal animals) and ** $p<0.01$ (compared with normal PCA model control). Statistical analysis of results was performed through one-way ANOVA followed by Dunnett's $t$-test. 


\section{Discussion}

In several developing countries, the prevalence of allergies, such as type I hypersensitivity disorders, is increasing at a higher rate. Genetic and environmental factors are major contributing factors in the development of allergic disorders. Nearly one in every four children in high-income nations have been diagnosed with allergic rhinitis, asthma, or eczema in the last three to four decades [25]. Small molecules, such as antagonists of leukotrienes or histamine receptors as well as steroid therapy, are the most widely used treatments for allergic disorders these days [26]. Traditional treatments, on the other hand, can cause unpleasant side effects, such as drowsiness, dry mouth, and sore stomach. C. militaris, a traditional East Asian medicine, is well known for its anti-inflammatory, antianemia, and anti-cancer properties. Anti-allergic remedies made from herbal constituents or extracts derived from ancient medicinal plants or fungi are gaining popularity because of their lower toxic effects. C. militaris, also known as Dong-Choong-Ha-Cho in Korea, is a medicinal fungus that has long been used to treat cancer [1], hyperlipidemia [27], hepatic cirrhosis [28], bronchitis [29], and asthma [30] in East Asia.

Food fermentation is an old food processing method that has long been used to increase the shelf life, organoleptic qualities, nutritional content, and bio-functionalities of food items. LAB are capable of producing a large quantity of secondary metabolites with good health advantages. In fact, some microbes can raise the amounts of a variety of beneficial chemicals, including antioxidants, phenolic compounds, peptides, and vitamins. Furthermore, fermented foods contribute to the modulation of the host's physiological balance and gut microbiota along with bioactive molecules. It is well known that edible fungi and their functional components have health benefits linked to the host gut microbiota. Bioactive antioxidants including glycolipids, aromatic phenols, and fatty acid derivatives may be found in edible fungi [31]. Well-known medicinal fungi, such as C. militaris, have been reported to have similar effects against many ailments. Because of its habitat, it is difficult to grow naturally. Recent studies have shown that cultured C. militaris contains high levels of amino acids [32]. There are few reports on fermented fungi [32]. Therefore, C. militaris grown on R. nulubilis was used in this study. Furthermore, recent advancements in the fermentation industry have focused on potentially bioactive chemicals that may be utilized as ingredients in functional food compositions for the treatment and management of various illnesses [33]. This study aimed to improve the bioactive nature of GRC by fermenting with the lactic acid bacterial strain (SC11) and to inhibit type I hypersensitive reactions using both in vivo and in vitro models. The augmented anti-allergic effects of GRC-SC11 might be attributed to its increased cordycepin content, antioxidant potential, and other ingredients, such as phenolic compounds. Herein, the Pediococcus pentosaceus bacterial strain was tested for fermenting the cultured GRC. Interestingly, we found that Pediococcus pentosaceus could ferment cultured C. militaris (GRC) but not naturally occurring C. militaris (data not shown). In this study, we developed a method for culturing GRC and GRC-SC11 to test their anti-allergic activities.

Many studies have found that oxidative stress, through the production of oxidant factors and the decrease of antioxidant factors, plays a key role in the development of allergic disorders [34]. Subsequently, altered antioxidant systems and an imbalance in the reactive oxygen species (ROS) are associated with allergy-associated ailments, such as asthma [35]. Activated inflammatory cells, such as eosinophils, neutrophils, monocytes, and macrophages, can generate ROS, which are linked to some extent with hypersensitivity [36]. Reduced antioxidant enzymes, such as superoxide dismutase, catalase, glutathione peroxidase, TAC, and glutathione levels, were found to be substantially lower in the blood and nasal mucosa of allergic rhinitis mice (Li et al., 2011). However, given the potential for traditional antioxidants to have poor pharmacokinetic characteristics, some researchers have proposed the production of novel antioxidant-based treatments for allergic diseases [37,38]. It has also been shown that $C$. militaris reduces the immuneinflammatory response and oxidative stress in $\operatorname{IgE} / \mathrm{Ag}$-stimulated allergic responses both in vitro and in vivo. 
One of the previous studies showed that the antioxidant activity of myrtle homogenate fermented with L. plantarum C2 was significantly higher than that of the non-fermented homogenate, as observed through the radical scavenging potential. Recently, our group also reported that fermentation increased the antioxidant activities of $R$. nulubilis using L. pentosus SC65 and P. pentosaceus ON89A bacterial strains [21]. Previous studies have demonstrated that polyphenol content, which is known to have antioxidant and antiinflammatory properties, was increased by phenolic esterase activity in LAB [39,40]. Our results showed that the content of cordycepin, which is an antioxidant, was higher in GRC-SC11 than in GRC. This was supported by the TAC assay results, SC11 fermentation resulted in an increase in the antioxidants potential, which was $>4$-times than that found in GRC. In this study, significantly augmented TAC activity and cordycepin content suggest that the anti-allergic effects of GRC-SC11 are, at least partially, mediated by its antioxidant activity. Cordycepin has been identified to be the key constituent of $C$. militaris, which exerts anti-inflammatory activity [41]. Previous studies have reported the protective effects of cordycepin on ovalbumin-induced allergic inflammation by suppressing Th17 responses in ovalbumin-sensitized mice [42]. The enhanced anti-allergic properties of GRC-SC11 are most likely due to antioxidants, such as novel isoflavonoids, cordycepin, and other bioactive constituents.

Mast cells are stimulated by IgE-regulated antigens via IgE specific receptors. Subsequently, the resulting cross linking of receptors, Syk, Gab2, and other downstream tyrosine kinases are activated [24]. As a result, Syk and Gab2 are promising targets for the development of allergy medicines. Activated Syk phosphorylates p38 and c-Jun, which are downstream signaling molecules. The Syk pathway is associated with the generation of pro-inflammatory cytokines [43]. Pro-inflammatory cytokines, such as TNF- $\alpha$ and IL-4 are produced from the activated mast cells [44]. Mast cell activation, leukocyte infiltration, allergic inflammation, and allergy-related processes are all triggered by these pro-inflammatory cytokines. TNF- $\alpha$ is involved in the regulation of allergic inflammation. Meanwhile, IL-4 is required for Th2 response expansion and induced B cell switching to IgE synthesis [45]. Our results showed that GRC-SC11 significantly decreased the protein expression of p-Syk, p-Gab, p-p38, and p-c-Jun in IgE/Ag-stimulated RBL-2H3 cells. Additionaly, GRC-SC11 significantly inhibited pro-inflammatory molecules, such as IL-4 and TNF- $\alpha$, in IgE / Ag-stimulated RBL-2H3 cells.

Previously, we reported novel isoflavonoid compounds that are similar to genistein or daidzein from C. militaris cultured on germinated soybeans (genistein 4-O- $\beta$-D-glucoside 4 "-O-methylate, daidzein 7-O- $\beta$-D-glucoside 4 "-O-methylate, genistein $7-\mathrm{O}-\beta$ - $\mathrm{D}$-glucoside 4 "-O-methylate, and glycitein 7-O- $\beta$-D-glucoside 4"-O-methylate) [46]. Remarkably, the novel isoflavonoids genistein and daidzein from $C$. militaris were grown on germinated soybeans and prominantly suppressed the degranulation in antigen-activated RBL-2H3 cells [19]. Previously, we observed that genistein $4-\mathrm{O}-\beta$-d-glucoside 4 "-O-methylate decreased the release of pro-inflammatory cytokines, $\mathrm{p}$-Syk, and phospho-extracellular signalregulated kinase (p-ERK), in antigen-induced RBL-2H3 cells and suppressed the PCA reaction [47]. It is conceivable that isoflavonoid compounds in GRC-SC11 might inhibit allergic activity by suppressing Syk activation.

PCA is a type I local allergy stimulated in mice by intradermal inoculating $\operatorname{IgE}$ into the ears and intravenous injecting antigen into the tails [22]. The interaction of the antigen and antibody enhanced the synthesis of allergy-associsted chemicals, like histamine in subcutaneous immune cells, as well as boosted the Evans blue dye's permeability and extravasation that was injected into the bloodstream with the antigen [22]. In comparison to the IgE/Ag-mediated allergy mouse model, we found that GRC-SC11 decreased the amount of extravasated Evans blue dye in the ear (Figure 5). Allergy-related trafficking molecules and endothelial selectins that can bind to immune cells are expressed as a result of IgE-mediated PCA reactions [48] and subsequently immune cells infiltrate the ear tissues [49]. Our results showed that GRC-SC11 substantially reduced the IgE-regulated PCA response by attenuating ear edema and decreasing the quantity of infiltrating inflammatory 
cells (Figure 6). These findings suggest that GRC-SC11 reduces the vascular expansibility and activates immune cells in the dermis induced by degranulation and produces cytokines of IgE/Ag-triggered mast and basophils cells, which is consistent with our in vitro results. In a previous study, we reported that the novel bioflavonoid genistein, 4-O- $\beta$-D-glucoside 4"-O-methylate, from C. militaris inhibited proinflammatory cytokines in antigen-triggered RBL-2H3 cells along with the PCA reaction [47].

\section{Conclusions}

We explored how the fermentation of cultured C. militaris is a beneficial approach to increase its bio-functionality. The fermentation of cultured $C$. militaris was carried out with the lactic acid bacterium, P. pentosaceus, isolated from a salted small octopus. An increase in the TAC of GRC-SC11 (>4 times) and cordycepin content $(42 \%)$ was observed in GRC-SC11 compared to GRC. We also observed the augmented anti-allergic activity of GRC-SC11 in the IgE/Ag-regulated allergic response by inhibiting the degranulation and decrease in the expression of proinflammatory cytokines (IL-4 and TNF- $\alpha$ mRNA) in RBL-2H3 cells, compared to GRC. Moreover, GRC-SC11 inhibited the phosphorylation of Gab2, p-Syk, and NF-kB in the FceRI-mediated signaling pathway along with MAPKs (p38/ c-Jun) in the IgE/antigen-stimulated RBL-2H3 cells, compared to GRC. Furthermore, GRC-SC11 demonstrated an anti-allergic activity in the PCA mice model by decreasing the allergy-related infiltration of cells and swelling. Conclusively, SC11-mediated fermentation increased the bio-functional ingredients of GRC, including cordycepin and antioxidants. GRC-SC11 inhibited the degranulation and suppressed the release of pro-inflammatory cytokines in IgE/Ag-activated RBL-2H3 cells. In addition, GRC-SC11 inhibited the signal transduction cascade responsible for type I hypersensitive allergic responses. This is supported by the in vivo experiment in which GRC-SC11 attenuated the IgE-mediated type I hypersensitivity reactions in the ear of BALB/c mice. This study highlights the potential of GRC-SC11 for developing fermented bio-functional foods and health supplements for the treatment and management of type I allergic diseases.

Supplementary Materials: The following are available online at https:/ /www.mdpi.com/article/10 $.3390 /$ nu13113849/s1, Table S1: Lactic acid bacteria strains used for fermenting GRC, Figure S1: Effect of GRC fermented with lactic acid bacteria on $\beta$-hexosaminidase assay from RBL-2H3 stimulated with IgE/Ag. Data were analyzed by one-way ANOVA/Duncan's $t$-test $(p<0.05)$. Different letters indicate significant differences between groups.

Author Contributions: Conceptualization, H.-J.P.; methodology, A.-R.P. and K.-R.D.; validation, A.-R.P. and K.-R.D.; formal analysis, A.-R.P. and K.-R.D.; investigation, A.-R.P., and K.-R.D.; resources, A.-R.P. and K.-R.D.; data curation, H.-J.P.; A.-R.P., and K.-R.D.; writing—original draft preparation, H.-J.P., A.-R.P., and K.-R.D.; writing-review and editing, H.-J.P., A.-R.P., and K.-R.D.; visualization, K.-R.D.; supervision, H.-J.P.; project administration, H.-J.P.; funding acquisition, H.-J.P. All authors have read and agreed to the published version of the manuscript.

Funding: This research was funded by the National Research Foundation of Korea (NRF) grant funded by the Korea government (MSIT, NO. NRF-2021R1F1A1048156).

Institutional Review Board Statement: The experiments were approved by the Institutional Animal Care and Use Committee at Gachon University (Gyeonggi-do, Republic of Korea, approval number: GIACUC-R2018001, approval date: 29 January 2018).

Acknowledgments: The authors acknowledge the Gachon University for partially supporting this study(GCU-2020-202002720001) and Dong Ki Park for sample preparation and technical support (Cell Activation Search Institute, Seoul, Korea).

Conflicts of Interest: There is no conflict of interest to declare. The funding providers had no role in the study design, execution, or publishing of the manuscript. 


\section{References}

1. Lee, H.H.; Lee, S.; Lee, K.; Shin, Y.S.; Kang, H.; Cho, H. Anti-cancer effect of Cordyceps militaris in human colorectal carcinoma RKO cells via cell cycle arrest and mitochondrial apoptosis. Daru J. Pharm. Sci. 2015, 23, 1-8. [CrossRef] [PubMed]

2. Park, H.-J.; Han, E.S.; Park, D.K.; Lee, C.; Lee, K.W. An extract of Phellinus linteus grown on germinated brown rice inhibits inflammation markers in RAW264. 7 macrophages by suppressing inflammatory cytokines, chemokines, and mediators and up-regulating antioxidant activity. J. Med. Food 2010, 13, 1468-1477. [CrossRef] [PubMed]

3. Tuli, H.S.; Sharma, A.; Sandhu, S.S.; Kashyap, D. Cordycepin: A bioactive metabolite with therapeutic potential. Life Sci. 2013, 93, 863-869. [CrossRef]

4. Yue, K.; Ye, M.; Zhou, Z.; Sun, W.; Lin, X. The genus Cordyceps: A chemical and pharmacological review. J. Pharm. Pharmacol. 2013, 65, 474-493. [CrossRef]

5. Liu, S.-N.; Han, Y.; Zhou, Z.-J. Lactic acid bacteria in traditional fermented Chinese foods. Food Res. Int. 2011, $44,643-651$. [CrossRef]

6. $\quad$ Pinto, M.G.V.; Franz, C.M.; Schillinger, U.; Holzapfel, W.H. Lactobacillus spp. with in vitro probiotic properties from human faeces and traditional fermented products. Int. J. Food Microbiol. 2006, 109, 205-214. [CrossRef]

7. Goulet, O. Potential role of the intestinal microbiota in programming health and disease. Nutr. Rev. 2015, 73 (Suppl. 1), 32-40. [CrossRef]

8. Choi, Y.J.; Yang, H.S.; Jo, J.H.; Lee, S.C.; Park, T.Y.; Choi, B.S.; Seo, K.S.; Huh, C.K. Anti-amnesic effect of fermented Ganoderma lucidum water extracts by lactic acid bacteria on scopolamine-induced memory impairment in rats. Prev. Nutr. Food Sci. 2015, 20, 126. [CrossRef]

9. Kormelink, T.G.; Arkesteijn, G.J.A.; van de Lest, C.H.A.; Geerts, W.J.C.; Goerdayal, S.S.; Altelaar, M.A.F.; Redegeld, F.A.; Hoen, E.N.M.N.; Wauben, M.H.M. Mast cell degranulation is accompanied by the release of a selective subset of extracellular vesicles that contain mast cell-specific proteases. J. Immunol. 2016, 197, 3382-3392. [CrossRef]

10. Kim, Y.-Y.; Je, I.-G.; Kim, M.-J.; Kang, B.-C.; Choi, Y.-A.; Baek, M.-C.; Lee, B.; Choi, J.K.; Park, H.R.; Shin, T.-Y.; et al. 2-Hydroxy-3methoxybenzoic acid attenuates mast cell-mediated allergic reaction in mice via modulation of the FceRI signaling pathway. Acta Pharmacol. Sin. 2017, 38, 90-99. [CrossRef] [PubMed]

11. Edwards, A. The mast cell and allergic diseases: Role in pathogenesis and implications for therapy. Clin. Exp. Allergy 2008, 38, 1242. [CrossRef]

12. Rizzi, A.; Crivellato, E.; Benagiano, V.; Ribatti, D. Mast cells in human digestive tube in normal and pathological conditions. Immunol. Lett. 2016, 177, 16-21. [CrossRef]

13. Theoharides, T.C.; Konstantinos-Dionysios, A.; Asimenia, A.; Danae-Anastasia, D.; Nikolaos, S.; Bodi, Z.; Shahrzad, A.; Magdalini, V.; Zuyi, W.; Alexandra, M.; et al. Mast cells and inflammation. Biochim. Biophys. Acta Mol. Basis Dis. 2012, 1822, 21-33. [CrossRef]

14. Ye, J.; Piao, H.; Jiang, J.; Jin, G.; Zheng, M.; Yang, J.; Jin, X.; Sun, T.; Choi, Y.H.; Li, L.; et al. Polydatin inhibits mast cell-mediated allergic inflammation by targeting PI3K/Akt, MAPK, NF-kB and Nrf2/HO-1 pathways. Sci. Rep. 2017, 7, 1-13. [CrossRef] [PubMed]

15. Abdala-Valencia, H.; Bryce, P.J.; Schleimer, R.P.; Wechsler, J.B.; Loffredo, L.F.; Cook-Mills, J.M.; Hsu, C.-L.; Berdnikovs, S. Tetraspanin CD151 is a negative regulator of FceRI-mediated mast cell activation. J. Immunol. 2015, 195, 1377-1387. [CrossRef] [PubMed]

16. Subhashini; Chauhan, P.; Singh, R. Ovalbumin-induced allergic inflammation lead to structural alterations in mouse model and protective effects of intranasal curcumin: A comparative study. Allergol. Immunopathol. (Madr) 2016, 44, 246-256. [CrossRef]

17. Hwang, S.-W.; Sun, X.; Han, J.-H.; Kim, T.-Y.; Koppula, S.; Kang, T.-B.; Hwang, J.-K.; Lee, K.H. Fermentation-Mediated Enhancement of Ginseng's Anti-Allergic Activity against IgE-Mediated Passive Cutaneous Anaphylaxis In Vivo and In Vitro. J Microbiol. Biotechnol. 2018, 28, 1626-1634. [CrossRef]

18. Jo, W.-R.; Park, H.-J. Antiallergic effect of fisetin on IgE-mediated mast cell activation in vitro and on passive cutaneous anaphylaxis (PCA). J. Nutr. Biochem. 2017, 48, 103-111. [CrossRef]

19. Oh, J.Y.; Choi, W.-S.; Lee, C.H.; Park, H.-J. The ethyl acetate extract of Cordyceps militaris inhibits IgE-mediated allergic responses in mast cells and passive cutaneous anaphylaxis reaction in mice. J. Ethnopharmacol. 2011, 135, 422-429. [CrossRef]

20. Wu, T.-F.; Chan, Y.-Y.; Shi, W.-Y.; Jhong, M.-T. Uncovering the molecular mechanism of anti-allergic activity of silkworm pupa-grown Cordyceps militaris fruit body. Am. J. Chin. Med. 2017, 45, 497-513. [CrossRef]

21. Lee, H.-J.; Park, H.-J. Germinated Rhynchosia nulubilis Fermented with Lactobacillus pentosus SC65 Reduces Particulate Matter Induced Type II Alveolar Epithelial Apoptotic Cell Death. Int. J. Mol. Sci. 2021, 22, 3660. [CrossRef]

22. Kwon, H.-K.; Park, H.-J. Park, Phellinus linteus Grown on Germinated Brown Rice Inhibits IgE-Mediated Allergic Activity through the Suppression of FceRI-Dependent Signaling Pathway In Vitro and In Vivo. Evid. Based Complement. Alternat. Med. 2019, 2019, 1485015. [CrossRef]

23. Chen, S.-S.; Gong, J.; Liu, F.-T.; Mohammed, U. Naturally occurring polyphenolic antioxidants modulate IgE-mediated mast cell activation. Immunology 2000, 100, 471-480. [CrossRef] [PubMed]

24. Siraganian, R.P.; De Castro, R.O.; Barbu, E.A.; Zhang, J. Mast cell signaling: The role of protein tyrosine kinase Syk, its activation and screening methods for new pathway participants. FEBS Lett. 2010, 584, 4933-4940. [CrossRef] [PubMed] 
25. Krishna, M.T.; Mahesh, P.A.; Vedanthan, P.K.; Mehta, V.; Moitra, S.; Christopher, D.J. The burden of allergic diseases in the Indian subcontinent: Barriers and challenges. Lancet Glob. Health 2020, 8, e478-e479. [CrossRef]

26. Harvima, I.T.; Levi-Schaffer, F.; Draber, P.; Friedman, S.; Polakovicova, I.; Gibbs, B.F.; Blank, U.; Nilsson, G.; Maurer, M. Molecular targets on mast cells and basophils for novel therapies. J. Allergy Clin. Immunol. Pract. 2014, 134, 530-544. [CrossRef]

27. Yu, M.; Yue, J.; Hui, N.; Zhi, Y.; Hayat, K.; Yang, X.; Zhang, D.; Chu, S.; Zhou, P. Anti-Hyperlipidemia and Gut Microbiota Community Regulation Effects of Selenium-Rich Cordyceps militaris Polysaccharides on the High-Fat Diet-Fed Mice Model. Foods 2021, 10, 2252. [CrossRef]

28. Heo, J.Y.; Baik, H.W.; Kim, H.J.; Lee, J.M.; Kim, H.W.; Choi, Y.S.; Won, J.H.; Kim, H.M.; Park, W.I.; Kim, C.Y. The efficacy and safety of Cordyceps militaris in Korean adults who have mild liver dysfunction. J. Korean Med. Sci. 2015, 7, 81-86. [CrossRef]

29. Hsu, C.-H.; Sun, H.-L.; Sheu, J.-N.; Ku, M.-S.; Hu, C.-M.; Chan, Y.; Lue, K.-H. Effects of the immunomodulatory agent Cordyceps militaris on airway inflammation in a mouse asthma model. Pediatr. Neonatol. 2008, 49, 171-178. [CrossRef]

30. Zheng, Y.; Li, L.; Cai, T. Cordyceps polysaccharide ameliorates airway inflammation in an ovalbumin-induced mouse model of asthma via TGF- $\beta 1 /$ Smad signaling pathway. Respir. Physiol. Neurobiol. 2020, 276, 103412. [CrossRef]

31. Singh, V.; Pandey, R.; Vyas, D. Antioxidant potentiality of Pleurotus ostreatus (MTCC142) cultivated on different agro wastes. Asian Pac. J. Cancer Prev. 2015, 5, 22-27.

32. Ji, Y.; Su, A.; Ma, G.; Tao, T.; Fang, D.; Zhao, L.; Hu, Q. Comparison of bioactive constituents and effects on gut microbiota by in vitro fermentation between Ophicordyceps sinensis and Cordyceps militaris. J. Funct. Foods 2020, 68, 103901. [CrossRef]

33. Verduzco-Oliva, R.; Gutierrez-Uribe, J.A. Gutierrez-Uribe, Beyond enzyme production: Solid state fermentation (SSF) as an alternative approach to produce antioxidant polysaccharides. Sustainability 2020, 12, 495. [CrossRef]

34. Shams, M.-H.; Jafari, R.; Eskandari, N.; Masjedi, M.; Kheirandish, F.; Hakemi, M.G.; Ghasemi, R.; Varzi, A.-M.; Sohrabi, S.-M.; Baharvand, P.A.; et al. Anti-allergic effects of vitamin E in allergic diseases: An updated review. Int. Immunopharmacol. 2020, 90, 107196.

35. Ahmad, A.; Shameem, M.; Husain, Q. Relation of oxidant-antioxidant imbalance with disease progression in patients with asthma. Ann. Thorac. Med. 2012, 7, 226. [PubMed]

36. Balestra, A.C.; Sandy, C.M.; Ramalho, F.; Júnior, A.A.J.; Contini, S.H.T.; Crevelin, E.J.; Carmona, F.; Pereira, A.M.S.; Borges, M.C. Aqueous Pyrostegia venusta (Ker Gawl.) Miers extract attenuates allergen-induced asthma in a mouse model via an antioxidant mechanism. J. Asthma 2021, 58, 808-818. [CrossRef]

37. Gref, A.; Rautiainen, S.; Gruzieva, O.; Håkansson, N.; Kull, I.; Pershagen, G.; Wickman, M.; Wolk, A.; Melén, E.; Bergström, A. Dietary total antioxidant capacity in early school age and subsequent allergic disease. Clin. Exp. Allergy 2017, 47, 751-759. [CrossRef] [PubMed]

38. Vollbracht, C.; Raithel, M.; Krick, B.; Kraft, K.; Hagel, A.F. Intravenous vitamin C in the treatment of allergies: An interim subgroup analysis of a long-term observational study. Int. J. Methods Psychiatr. Res. 2018, 46, 3640-3655. [CrossRef]

39. Webber, D.M.; Hettiarachchy, N.S.; Li, R.; Horax, R.; Theivendran, S. Phenolic profile and antioxidant activity of extracts prepared from fermented heat-stabilized defatted rice bran. J. Food Sci. 2014, 79, H2383-H2391. [CrossRef]

40. Donaghy, J.; Kelly, P.F.; McKay, A.M. Detection of ferulic acid esterase production by Bacillus spp. and lactobacilli. Appl. Microbiol. Biotechnol. 1998, 50, 257-260. [CrossRef]

41. Won, S.-Y.; Park, E.-H. Anti-inflammatory and related pharmacological activities of cultured mycelia and fruiting bodies of Cordyceps militaris. J. Ethnopharmacol. 2005, 96, 555-561. [CrossRef]

42. Tianzhu, Z.; Shihai, Y.; Juan, D. The effects of cordycepin on ovalbumin-induced allergic inflammation by strengthening Treg response and suppressing Th17 responses in ovalbumin-sensitized mice. Inflammation 2015, 38, 1036-1043. [CrossRef] [PubMed]

43. Duan, W.; Wong, W.F. Targeting mitogen-activated protein kinases for asthma. Curr. Drug Targets 2006, 7, 691-698. [CrossRef] [PubMed]

44. Kim, H.I.; Hong, S.H.; Ku, J.M.; Kang, S.; Kim, T.Y.; Shin, Y.C.; Ko, S.G. Tonggyu-tang, a traditional Korean medicine, suppresses pro-inflammatory cytokine production through inhibition of MAPK and NF- $\mathrm{B}$ activation in human mast cells and keratinocytes. BMC Complement. Altern. Med. 2017, 17, 1-8. [CrossRef] [PubMed]

45. Kalesnikoff, J.; Galli, S.J. New developments in mast cell biology. Nat. Immunol. 2008, 9, 1215-1223. [CrossRef]

46. Han, J.Y.; Im, J.; Choi, J.N.; Lee, C.H.; Park, H.J.; Park, D.K.; Yun, C.-H.; Han, S.H. Induction of IL-8 expression by Cordyceps militaris grown on germinated soybeans through lipid rafts formation and signaling pathways via ERK and JNK in A549 cells. J. Ethnopharmacol. 2010, 127, 55-61. [CrossRef]

47. Park, N.K.; Choi, W.S.; Park, H.-J. Antiallergic activity of novel isoflavone methyl-glycosides from Cordyceps militaris grown on germinated soybeans in antigen-stimulated mast cells. J. Agric. Food Chem. 2012, 60, 2309-2315. [CrossRef]

48. Luster, A.D.; Alon, R.; Von Andrian, U.H. Immune cell migration in inflammation: Present and future therapeutic targets. Nat. Immunol. 2005, 6, 1182-1190. [CrossRef]

49. Lee, J.H.; Kim, J.W.; Kim, D.K.; Kim, H.S.; Park, H.J.; Park, D.K.; Kim, A.R.; Kim, B.; Beaven, M.A.; Park, K.L.; et al. The Src family kinase Fgr is critical for activation of mast cells and IgE-mediated anaphylaxis in mice. J. Immunol. 2011, 187, 1807-1815. [CrossRef] 